Forthcoming in the Routledge Handbook of Hellenistic Philosophy, K. Arenson (ed). Please cite the published version.

Abstract for "Stoic Cosmopolitanism and Environmental Ethics":

This chapter considers how ancient Stoic cosmopolitanism - roughly, the claim all human beings are members of the same "cosmopolis", or universal city, and so are entitled to moral concern in virtue of possessing reason - informs Stoic thinking about how we ought to treat non-human entities in the environment. First, I will present the Stoic justification for the thesis that there are only rational members of the cosmopolis - and so that moral concern does not extend to any non-human part of the natural world - and explore the foundations of these views in Stoic physics. Next, I will show that, like other anthropocentric theories, Stoic cosmopolitanism allows for environmental preservation and protection of non-human entities, so long as these activities ultimately benefit human beings. However, because the Stoics include the appreciation of natural beauty as a component of the happy life, this justification is not as feeble as it might seem. Humans are naturally set up to contemplate the order and complexity of the universe, and so environmental degradation and species loss, in marring this harmonious system, frustrates the achievement of the human goal. After exploring these facets of Stoic philosophy, and assessing to what extent they might justify environmental conservation, I will close with a critical appraisal of Stoic theory - specifically, of the claims that (i) only humans possess reason and (ii) only rational creatures are deserving of moral concern. 


\title{
Stoic Cosmopolitanism and Environmental Ethics
}

\author{
Simon Shogry
}

Consider the following sylvan scene. A babbling brook trickles through a virgin forest. Deer bend to drink from its clear waters, and birds sing from the canopies of ancient trees, which hang over a dense undergrowth teeming with plant and insect life. Many of the flora and fauna species here are endangered. And although a full scientific survey is not yet complete, a mining company reports that extracting the forest's lumber and other resources would increase profits considerably. Their envisioned operation would attract major investments, boosting the regional economy and creating hundreds of stable jobs.

One task of environmental ethics is to clarify whether this kind of mining operation is morally justified, by articulating and defending a general theory of environmental value. In developing such a theory, environmental ethicists identify which natural entities possess "intrinsic value". This technical phrase can be understood in different ways (see Jamieson 2008: 68-75 and Regan 1981: 22), but for our purposes here amounts to the following: an entity has intrinsic value if and only if its interests are morally significant. The mining company's drill, for instance, clearly lacks intrinsic value. Whether the drill is oiled or not, whether it is discarded after one use or a hundred - in general, the condition and survival of the drill - is not something that moral agents should consider in deciding how to act. By contrast, whatever has intrinsic value deserves our moral concern, and we ought to take account of its interests in assessing whether to perform an action affecting it. A theory of environmental value therefore determines how far into nature morality extends. Do the flora and fauna of our sylvan scene - the individual plants and animals as well as the larger ecosystem that they make up - have the same moral status as the mining company's drill?

Many of the founding studies in contemporary environmental ethics (e.g. Routley 1973) argued against one theory of environmental value - the anthropocentrist theory - on 
which only human beings have intrinsic value. Thus, in our case above, to decide whether the mining operation is justified, this theory would have us consider the effects of the forest's preservation or destruction on present and future humans, e.g., the aesthetic and scientific benefits of its preservation and the economic value of its destruction. But no further features of the case would be relevant for moral assessment, because the anthropocentrist theory denies intrinsic value to the plants and animals living within the forest, as well as to the river and the forest ecosystem as a whole. On the anthropocentric view, all non-humans are just like the mining company's drill, morally speaking. So although the mining operation would despoil, kill, and maim the non-human entities living in the forest, this fact has no moral bearing apart from its effects upon present or future humans.

Over the last fifty years, frustrated by the perceived limitations of anthropocentrism, environmental ethicists have articulated more expansive accounts of which natural entities have intrinsic value (for general discussion, see Campbell 2018: 57-60). One motivation for abandoning anthropocentrism is that, in the view of some environmental ethicists, the theory fundamentally misunderstands humanity's place in nature: rather than conceive of humanity as a dominant, all-consuming force - an attitude argued to be implicit in the anthropocentric theory - we should instead adopt the perspective of a reverential and humble peer. Others maintain that the anthropocentric theory is "speciesist", insofar as it grounds moral concern on an arbitrary characteristic: whether one is a member of the species Homo sapiens. In any event, by broadening the circle of moral concern beyond the human, non-anthropocentric theories justify more cases of environmental preservation. Although it is possible to defend many instances of conservation solely by its effects on present and future humans - consider the massive toll on human life and economic activity that will be exacted by climate change the justification for environmental preservation becomes easier to establish if one assigns intrinsic value to all sentient creatures (Singer 2011, 1975) or to all living creatures (Taylor 
1986), or even to non-living ecological systems (Rolston 1975, Naess 1973) and "the land" itself (Leopold 1949).

Contemporary environmental ethics thus investigates which natural entities have intrinsic value, and what kind of attitude we humans should cultivate towards the environment, with a view to determining whether particular cases of environmental protection are morally justified. The purpose of this essay is to examine whether there is anything in ancient Stoic philosophy - in its early Greek phase as well as its Roman reception - relevant to these contemporary projects, and to reconstruct how the Stoics would have approached these central questions of environmental ethics.

Within ancient Stoicism, I will focus on their celebrated cosmopolitanism - a dimension of Stoic thought we now understand better thanks to recent scholarly attention (Vogt 2008; Brennan 2005; Schofield 1991). But assessing how Stoic cosmopolitanism engages with questions of environmental value will require us to look at other Stoic views as well. This is due to the systematic, interlocking character of Stoic philosophy. To articulate and defend their ethical theory, the Stoics draw on their account of the natural world. Indeed, it is impossible to appreciate the motivations for Stoic cosmopolitanism - roughly, the claim that all human beings are members of the same "cosmopolis", or universal city, and so are entitled to moral concern - without taking note of central claims in Stoic physics.

In certain respects, Stoic physics chimes well with the perspective of some environmental writers today. The cosmos, as the Stoics conceive of it, is a living being, a unified organism of which every human, animal, insect, plant, and rock is an integral part. There is thus no sense in Stoic thought in which the human being is separated off from nature as a whole. As we will see, this physical thesis informs the Stoics' ethical outlook, which identifies a life "in agreement with nature" as the correct object of all human striving. The 
order and structure displayed in nature thus provides a template, on the Stoic account, for the best kind of human life.

However, it must be noted straightaway that Stoic ethics, and their cosmopolitanism in particular, stands on philosophical foundations deeply alien to the mainstream of today's environmental ethics. First and foremost, the Stoics are committed anthropocentrists. Our ancient sources are unambiguous that the Stoics hold that justice does not extend to nonhuman animals, much less to plants or "the land", insofar as only humans possess reason, and justice requires us to consider the interests of reason-possessing agents only. ${ }^{1}$ Here the Stoics effectively deny intrinsic value to any non-human part of the natural world, and this claim is also registered in Stoic cosmopolitanism. Although we ought to see any human, regardless of their station, as affiliated with us and worthy of moral concern, no animal or plant deserves this status because they lack reason. Apparently worse still, Stoic physics is explicitly teleological. The Stoics maintain that, in many cases, animals are created for the sake of humans, and plants for the sake of animals, and so argue from principles considered hopelessly antiquated, if not repugnant, from the perspective of modern biology.

Given these cross-currents in ancient Stoic thought, assessing the relevance of their cosmopolitanism for contemporary environmental ethics is a delicate task. More is required than noting superficial resemblances between Stoic claims and the environmental literature today. This essay attempts to clarify how Stoicism might be relevant to environmental questions by paying careful attention to the Stoics' own subtle views, which defy simplistic sloganeering.

First, I will present the Stoic justification for the thesis that there are only rational members of the cosmopolis - i.e., that moral concern extends to our fellow human and no further - and explore the foundations of this view in Stoic physics. Next, I will show that, like other anthropocentric theories, Stoic cosmopolitanism allows for environmental preservation 
and protection of non-human entities, so long as these activities ultimately benefit human beings. However, this justification for environmental protection is not entirely feeble, in part because the Stoics include the appreciation of natural beauty as a component of the good life. Humans are set up by nature to contemplate the order and complexity of the physical world, and so environmental degradation, in marring this harmonious system, frustrates humanity's natural goal. After exploring these facets of Stoic philosophy, and assessing to what extent they might justify environmental conservation, I will close with a critical appraisal of Stoic theory - specifically, of the claims that (i) only humans possess reason and (ii) only rational creatures are deserving of moral concern - and consider whether they are indispensable to the Stoic project. In exploring these issues, I hope to show that Stoic cosmopolitanism, and the broader ethical and physical framework of which it is a part, can fruitfully engage with today's questions of environmental value.

\section{Stoic Cosmopolitanism and Stoic Physics}

Like other Hellenistic schools of philosophy, the Stoics call upon their theory of the natural world to defend their account of the best human life. Stoic cosmopolitanism in particular depends on key features of Stoic physics, which we should now set out.

The universe, as the Stoics characterize it, is not a collection of inert matter moving according to fixed laws, as in the Newtonian model, but rather a living organism, embracing all things within it as its parts. What unites these parts into a single animal is the presence of Zeus, conceived of not as a fickle Olympian but an immanent corporeal principle of activity and change. Zeus is present everywhere in the cosmos - in humans, animals, insects, plants, rocks, as well as the fundamental physical elements, earth, air, fire, and water - regulating these natural entities with his thought and executing an all-encompassing rational plan for the course the universe will take. The Stoic universe is therefore governed by an enormously complex, occurrent act of thinking, carried out by a divine mind present everywhere within it 
(Cooper 2012: 152-153; Cooper 2004: 224-228). Indeed, as the product of Zeus's rationality, the universe is said to be providentially organized: everything that actually transpires in the world instantiates the best possible arrangement (Cicero De Natura Deorum [= DND] 2.8687; for general discussion see Sedley 2007: 210-238). Thanks to Zeus's meticulous administration, the cosmos we live in is a beautiful, well-ordered creation, with every kind of plant and animal making a distinct contribution to a single, overarching living system.

From this cursory summary, one can imagine how Stoics physics could hold interest for environmental ethicists interested in the claim that humans do not stand apart from nature but instead are fully integrated within it. In fact, Stoic thinking seems to have inspired the pantheism of the $17^{\text {th }}$-century philosopher Baruch Spinoza, whose work in turn influenced the founders of deep ecology in the $20^{\text {th }}$-century (Brennan and Lo 2016). These writers saw the roots of their "biospheric egalitarianism" in the conception of nature as pervaded by divine reason, and some affinity between their view and the Stoics' has been proposed (Cheney 1989; see critical discussion in Stephens 1994 and Castelo 1996).

But while it is true, on Stoic theory, that humans, animals, plants, and rocks are all parts of the cosmos, humans retain a privileged status, as "offshoots" (DL 7.143) or "allies" (Seneca Ep. 92.70) of Zeus. Here the Stoics mean to express that, compared to every other part of the cosmos, human beings have received a more concentrated portion of divine rationality, a grant which enables us to use reason in our own right. Zeus's rationality can be seen everywhere in the cosmos - in the keen perceptual and locomotive powers of animals, for instance, or in the regular blossoming of plants, or even in the relatively unimpressive fact that rocks maintain their shape over time - but it is only in humans that Zeus has set up our minds with the capacity to think linguistically-articulate thoughts and to set our own course of action. These sophisticated cognitive powers of the human mind - our rationality - make us the cosmic part whose nature most closely approximates that of the whole (DL 7.86). 
That humans are distinguished from plants and animals by our use of reason is a physical claim of great importance for Stoic ethics, as it forms the crux of their teleological analysis of human nature. To exercise reason is characteristic of human beings, and to exercise it virtuously - to think correct thoughts about one's situation and to act properly on that basis - suffices for happiness and is the single goal of a well-lived human life. But while this accomplishment is out of reach for plants and animals, as they lack reason altogether (Seneca Ep. 76.9-10), the Stoics still posit natural goals in plant and animal life, and explain the success of such lives according to whether their natural goals are attained (Klein 2016: 180-191; Stephens 2014: 212-222). As Cicero’s Stoic spokesman remarks:

The crops and fruits which the earth brings forth were made for the sake of animals, and the animals which it brings forth were made for the sake of humans (the horse for transport, the ox for ploughing, the dog for hunting and guarding). The human being himself has come to be in order to contemplate and imitate the world, being by no means perfect, but a tiny constituent of that which is perfect. (DND 2.37, tr. after Rackham)

And again later in the same work:

All the things there are in the universe that are used by human beings have been created and provided for the sake of human beings. (DND 2.154, tr. after Rackham)

Up and down the scale of nature, life is generated to fulfill a goal. And in many cases - horses, dogs, and oxen, for example - this goal will include some use for human beings (see also Porphyry, LS 54P). Indeed, Cicero's Stoic spokesman goes on to posit an anthropocentric purpose not only of the distribution of forests, mountains, and sea, but also of the abundance of minerals buried beneath the earth (DND 2.159-162, discussed in Sedley 2007: 234-5). We will consider in a moment the implications of this view for the Stoic 
account of the proper treatment of animals and the environment at large. But for now we should examine how Stoic teleology supports their cosmopolitanism.

Here the Stoic doctrine of oikeiôsis (“affiliation”, "appropriation”) becomes relevant (Vogt 2008: 99-110; cf. Stephens 1994: 279-282). Although they regard some creatures, like the horse, as teleologically ordered for human use, the Stoics also recognize natural goals that do not directly refer to humans. For instance, bulls naturally form horns for the sake of defense (Hierocles, LS 57C); turtles have shells for protection (Seneca, LS 57B); and bees cooperate with each other to construct honeycombs (Cicero, De Finibus [= DF] 3.63; cf. DND 2.123-4). Indeed, Cicero reports that the early Stoic Chrysippus catalogued the teleological functions of myriad plant and animal species, specifying the natural goals implicit in their physical constitutions (DF 4.28). In a further step, the Stoics claim that every animal is born with the capacity to perceive their own teleological function (a capacity for "self-perception") and is attracted to whatever preserves this functioning (to what is oikeion to the animal in question). As we see in toddlers struggling to take their first steps, or in overturned turtles attempting to right themselves, animals pursue the proper condition of their constitutions even in the face of pain (DL 7.85-86). The pursuit of teleological success, straight from birth, is thus hard-wired into every animal, as yet another beneficial dispensation from providential Zeus.

This teleological regularity in nature, which draws every animal to what is oikeion ("affiliated" or "appropriate") to it, is taken to support the Stoic view of cosmopolitan justice, on which all fellow humans must be treated with moral concern. The connection between these ideas is difficult to see, unless we recall a few presuppositions of the Stoic argument. First, the inborn orientation to what is appropriate obtains not only for animals but for humans as well, as a general fact about the behavior of animate creatures. Second, in parallel with other "cradle arguments" from the Hellenistic period, the Stoics maintain that facts 
about the behavioral patterns of newborns inform how we adult humans ought to act (Klein 2016, Brunschwig 1986). Finally, the Stoics regard mutual cooperation and sociality as appropriate for human beings - an essential feature of what it means to be human and part of our natural goal at all stages of life (Plutarch, LS 57E) - just as it is for other creatures such as bees or ants:

The very fact of being human requires that no human be considered a stranger to any other. Some of our bodily parts, for example our eyes and ears, are as it were created just for themselves. Others, for example legs and hands, also enhance the utility of the other parts. In the same way, certain animals of great size are created merely for themselves... [but] take ants, bees, and storks they act for the sake of others. Yet the ties between human beings are far closer. Hence we are fitted by nature to form associations, assemblies, and states. (Cicero DF 3.63, tr. Woolf modified)

Humans are set up by nature to create bonds with one another - we are "suited for community" (koinônikon), as another source puts it (Arius in Stobaeus, Ecl. 2.109; cf. Seneca On Anger 1.5.2-3; 2.31.6-7). This teleological orientation toward forming associations of mutual concern accounts for present human behavior (e.g., why we live in cities) and also sets an ideal for how we should behave (giving due regard to the interests of all human beings, as members of a single cosmic city) (Hierocles, LS 57D). The Stoics thus find an explanation for the human tendency to form communities - and a sketch of the best kind of human community - in the teleological architecture of nature. Given the kind of beings we are and the natural goals we have, we ought to treat every human being as affiliated with us and view them as worthy of concern. Adopting this cosmopolitan perspective is required if we are to live "in agreement with nature". 
But if we are to live as nature intends, why do the Stoics think that our concern must extend to all human beings? That this is the Stoic view is confirmed in many sources (see Vogt 2008: esp. 86-90; cf. Schofield 1991: 104-111). In a memorable image, the Stoic Hierocles draws a series of concentric circles, standing in for the humans we are affiliated with, beginning with the self and extending outwards, from family to friends to countrymen until reaching a final circle encompassing "the whole human race":

It is the task of a well-tempered man, in his proper treatment of each group, to draw the circles together somehow towards the center, and to keep zealously transferring those from the enclosing circles into the enclosed ones.

(Hierocles, LS 57G, tr. LS)

Stoic cosmopolitanism requires us to feel affiliated with members of all these circles, even the "most distant Mysian" (LS 57H), to transfer them to the center of our concern and treat them fairly (Cicero De Officiis 1.12, 3.42).

One accomplishment of recent scholarship has been to root this claim in the Stoic idea that all adult humans possess rationality (Schofield 1991: 67-74; cf. Vogt 2008: 105-110). On this interpretation of the Stoic view, it is because we share rationality that the collection of human beings constitutes a single community living under a common law. As Marcus Aurelius argues:

If mind is common to us, so also is reason, in virtue of which we are rational. If that is so, the reason which prescribes what is and is not to be done is also common. If that is so, law also is common; if that is so, we are citizens; if that is so, we partake in a kind of political system; if that is so, the universe is as it were a city. (Med. 4.4, tr. Schofield; cf. Cicero De Leg. 1.31, DND 2.79, 148) In this compressed inference, Marcus argues that all human beings are bound by a common law and live in a single city - the universe - insofar as we all possess reason. The 
train of thought here is hard to follow if we assume that rationality consists in mere meansends calculations. But the Stoic conception of reason is much more robust: whoever shares in reason thereby also shares a commitment to a set of values prescribing "what is and is not to be done", as Marcus puts it (Schofield 1991: 67-72; Frede 1994). All rational creatures come with a basic conceptual orientation that speaks to how we should treat one another, and the Stoics regard these shared principles of sociality as justifying the claim that all human beings constitute a single community of cooperative concern (Magrin 2018). Of course, the Stoics allow that our basic conceptual orientation can be further refined - to do this we must employ the Stoic system of logic and dialectic - and that the end result of this refinement is wisdom and Sagehood. In the Sage, we see rationality fully developed, a human mind perfectly in sync with the thinking of Zeus as he governs the cosmos (DL 7.87-88).

According to this reconstruction of Stoic cosmopolitanism, the shared possession of rationality entitles all human beings to membership in a single community. In recognizing this fact, and seeing all humans as the proper object of our affiliation, we realize our natural goal of mutual cooperation. Sages - perfected human agents - have earned full citizenship in the cosmopolis, by internalizing and obeying the common law binding all rational creatures as such (Vogt 2008: 90-93). But even those falling short of Sagehood - the vast majority of human beings - are not excluded from the community of moral consideration, insofar as our shared rational nature endows us, if only inchoately, with the same basic norms of proper sociality.

\section{Stoic Anthropocentrism and Justifications for Environmental Protection}

For those interested in today's environmental ethics, however, the Stoic celebration of reason has a dark side, inasmuch as the Stoics maintain further that, other than the gods, only humans possess reason, and so exclude all non-human parts of the cosmos from the realm of moral concern. This anthropocentric implication is spelled out explicitly in our most 
authoritative source for Stoic political philosophy, immediately following its presentation of cosmopolitanism:

But though they hold that there is a code of law which binds humans together, the Stoics do not consider that any such code exists between humans and other animals. Chrysippus made the famous remark that all other things were created for the sake of humans and gods, but that humans and gods were created for the sake of their own community and society; and so humans can use animals for their own benefit with impunity. He added that human nature is such that a kind of civil code mediates the individual and the human race: whoever abides by this code will be just, whoever breaches it unjust. (Cicero, DF 3.67, tr. Woolf)

As we might have guessed from the fact that Hierocles's circles embrace "the whole human race" but no further, cosmopolitan justice, on the Stoic view, requires giving moral concern to all human beings but to no part of the cosmos that is not human (cf. Plutarch, LS 67A and discussion in Vogt 2008: 86-90). Indeed, this seems to have been one of the main theses of Chrysippus's now-lost work On Justice: "there is no relation of justice between us and the other animals, on account of their dissimilarity" (DL 7.129). Presumably, this “dissimilarity" consists in their lack of rationality (Seneca Ep. 73.9-10; Porphyry De Ab. $3.1 .2) .^{2}$

Given this anthropocentric commitment, on what grounds could the Stoics endorse environmental protection? Justice, as we have seen, demands due regard for the members of the cosmopolis, and so for all human beings but no non-rational plant or animal. Thanks to excellent recent scholarship, we can now spell out more precisely what this due regard amounts to (Klein 2015; Cooper 2012; Vogt 2008; Brennan 2005), and thus shed light on how the Stoics might justify conservation activities. 
Elsewhere, the Stoics define justice as the "knowledge which distributes value to each", that is, to each person (Arius, LS 61H, my translation). "Value" (axia) is a technical term in Stoic ethics, and attaches to things like health, wealth, bodily pleasure and strength items facilitating a normal human life and appropriate for us to select (DL 7.105).

Controversially, however, the Stoics deny that happiness requires us to possess a certain amount of valuable items. If we are virtuous, then nothing else is needed to live a life in agreement with nature: whether healthy or sick, rich or poor, the virtuous person is happy (Cicero DF 3.33, 3.42). For this reason, health, wealth, and so on are said to be "preferred" but "indifferent": their opposites - disease, poverty, etc. - are likewise indifferent but “dispreferred" (DL 7.102-103; Cicero DF 3.50). These labels should be used with caution, however, since the Stoics do not recommend diffidence or aloofness toward indifferents. Although their possession is not necessary for happiness, these items have value, and, tellingly, the Stoics describe them as the "matter" of virtue (Plutarch Com. Not. 1069e). What valuable items we select, and why, reveals whether our thoughts agree with Zeus and display virtue (cf. Arius, LS 58K; see Klein 2015 for detailed discussion).

Consistent with this understanding of indifferents and virtue, the Stoics argue that acts of justice are those which distribute indifferents among humans fairly. This is the idea contained in the Stoic definition of justice quoted above: the just agent knows how to apportion items of value to whom, i.e., what the fair distribution of indifferents is, in whatever situation she finds herself. Scholars dispute whether the just agent arrives at this view on the basis of general rules concerning the distribution of indifferents (Striker 1987), or if instead such determinations must be made case-by-case (Inwood 1999). In any event, the Stoics think that in every scenario there is a fact about what the fair distribution of value is, and that this fact is known by the just agent. 
Cosmopolitan justice, then, forbids destruction of the environment whenever this destruction would produce an unfair distribution of value among human beings. For instance, suppose that, by polluting a river with toxic waste, a chemical corporation cuts costs and increases the wealth of its shareholders. But this river is also a water source for a nearby town. Due to the disease, death, and economic destitution resulting from the pollution, this act is unjust. The gain in value for one group (the shareholders) comes about through a loss of value of another (the townsfolk) and thus displays the hallmark of injustice, on the Stoic view:

It is alien to justice to deprive someone else in order to acquire for oneself. (Cicero DF 3.70, tr. Brennan)

For one human being to deprive another in order to increase their welfare at the cost of the other person's welfare is more contrary to nature than death, poverty, pain, or any other things that can happen to one's body or one's external possessions. For, to begin with, it destroys human communal living and society. For if we are each at the ready to plunder and carry off another's advantages for the sake of our own, that will necessarily demolish the thing that is in fact most according to nature, namely the social life of human beings. (Cicero De Officiis 3.21, tr. Brennan)

In polluting the river to gain money, the shareholders take more than their fair share of preferred indifferents and thereby act unjustly. Here the Stoics seem to emphasize the antisocial attitude implicit in any unfair distribution of indifferents - rather than the deprivation of value itself - as what makes such actions unjust. If one acquires value by means of depriving it from others, one thereby evinces a vicious state of mind insofar as one disrespects one's fellow members of the cosmopolis and misunderstands the proper scope of one's affiliations. ${ }^{3}$ Furthermore, regardless of its profitability, the chemical pollution would 
despoil the town's communal property. This fact is morally significant for the Stoics, since their account of justice requires that we respect such property (Cicero De Officiis 1.20-1; DF 3.67; see detailed discussion in Brennan 2005: 204-210).

In general, then, Stoic principles prohibit environmental degradation whenever it disrespects the members of the cosmopolis - either by violating their property or imposing an unfair distribution of value - with the result that the perpetrator engages in vice.

What about the effect of pollution on non-human entities? In our scenario above, fish would be poisoned, plants would wither, and the riparian mammals would die painful deaths. ${ }^{4}$ The river itself would be deformed and the functioning of the biome altered. But considered independently of how they impact the distribution of value among human beings, these facts are morally irrelevant. Because justice extends only to rational creatures, and because only humans naturally acquire reason, the loss of life and health in non-humans is morally insignificant, in and of itself.

In principle, then, we can see why Cicero's Stoic spokesman remarks that "humans can use animals for their own benefit with impunity" (DF 3.67). So long as it would not affect the distribution of value among human beings, there is no moral reason to treat animals, plants, or "the land" one way or another (cf. Cicero DND 2.151-2). Of course, more often than not, the way we treat non-humans does have such an effect. Besides the obvious example of climate change, factory-farming practices may ultimately undermine global human health and so would be regarded as unjust on Stoic theory, since this deprivation of value comes about for the sake of private profit.

Before leaving things here, we must examine one further aspect of Stoic thought that may allow for more environmental conservation than our reconstruction so far suggests. In one passage of his Meditations, Marcus Aurelius recommends conscientious treatment of animals and other non-rational entities: 
In the case of non-rational animals and objects and things in general, treat them with generosity of spirit and freedom of mind, since you have rationality and they do not. In the case of human beings, since they have rationality, treat them in a way that befits membership in a community (koinônikôs). (Med. 6.23 , tr. Gill, modified)

The second sentence reflects the well-attested Stoic thought that our shared rationality entitles all human beings to membership in the cosmopolis and thus to full moral consideration. By contrast, we may be tempted to dismiss the first sentence of the quotation as a theoretically-uninformed aside. After all, the Stoics exclude non-humans from the cosmopolis and characterize many animals as teleologically ordered for human use. So why should we treat them "with generosity of spirit" (megalophronôs)? However, orthodox Stoic principles may yet legitimize the considerate attitude Marcus expresses here.

In his work On Nature, Chrysippus is reported to have described the teleological purpose of certain animals, such as the peacock, as follows:

Beauty is the purpose for which many of the animals have been produced by nature, since nature is a lover of the beautiful and delights in diversity ... the peacock's tail on account of its beauty is the purpose for which the peacock has come to be. (Plutarch St. Rep. 1044c, tr. after Cherniss)

Just as the natural goal of the horse is human transportation (Cicero DND 2.37), and the pig, human consumption (Porphyry, LS 54P; Cicero DND 2.160), the peacock also comes about for the sake of human use (see detailed discussion in Sedley 2007: 231-238). But while the horse and pig facilitate the proper functioning of the human body, the peacock seems to contribute to the proper functioning of the human mind. The natural goal for human beings is to live in agreement with nature, or, equivalently, to employ our rational nature virtuously (Arius, LS 63A). One instance of virtuous activity is the contemplation of the beauty of the 
cosmos - its "diversity", rational structure, and harmonious order (cf. DL 7.100-101). "The human being himself has come to be in order to contemplate and imitate the world", as Cicero's Stoic spokesman puts the point (DND 2.37, tr. above). And as Epictetus comments: [Zeus] introduced the human being as a student of [Zeus] and his works - and not merely as a student but also as an interpreter of these things. Therefore it is wrong for humans to begin and end where the non-rational animals do; we should rather begin where they do and end where nature has ended in our case. Nature ended at studying and attending to things and at a way of life in harmony with nature. See to it then that you do not die without having studied these. (Diss. 1.6.19-22, tr. after LS)

To fulfill our natural goal - to accomplish the task for which Zeus created us - we must study the complexity and teleological structure displayed in Zeus's creation. Contemplation of the physical world is required for, and a part of, the best human life. ${ }^{5}$

We should note, of course, that human activities did not pose a threat to global biodiversity in the era when Stoic ideas were formulated, and that the ancients had no inklings of the scale of species and habitat loss happening today. But given the Stoic injunction to contemplate the cosmos as part of the good life - and their conception of nature as teleologically structured, with every cosmic part contributing to the orderliness and beauty of the whole - it is tempting to attribute to them the following view. When carried out on a massive scale, environmental destruction threatens the virtuous exercise of our rationality, and so frustrates our natural goal, insofar as it robs us of suitable objects of contemplation. Human-caused species loss tampers with Zeus's perfectly constructed creation (cf. Cicero, DND 2.88) by removing a stable contribution to cosmic order - a species of plant or animal and so hinders our appreciation of the well-arranged whole. When a species goes extinct, 
nature becomes that much less "diverse" (cf. Plutarch above), with the result that virtuous agents have fewer opportunities to think the excellent thoughts that constitute a happy life.

Admittedly, there is no direct evidence that these ideas were arrayed by the Stoics to justify environmental protection in this way. And there is certainly no systematic theory lying behind these observations that would, e.g., adjudicate conflicts between the preservation of cosmic teleological order and the amplification of value for human beings. And it may be that contemplating nature's beauty does not require the actual existence of such beauty - would film-reels of a bucolic scene be enough? I submit, however, that the peculiar resources of the Stoic system gesture towards an additional justification for environmental protection besides respect for communal property and fair distribution of value. Conservation of the environment provides an indispensable venue for the contemplative activity of the Sage, by allowing her to appreciate the harmony and beauty present in the cosmic order and thus attain the human goal.

\section{Stoicism without anthropocentrism?}

In closing, I will now assume a more critical stance toward Stoic cosmopolitanism, raising doubts that may have already crossed the reader's mind.

First, one might question the anthropocentric claim that all and only humans possess rationality. While the Stoics grant that children are not born rational -- they are said to acquire rationality at a later age (Aëtius, SVF 2.83) - one might still object that it is not the case that all adults possess reason. Accident victims who have fallen into a "persistent vegetative state", as well as the developmentally challenged, seem to be obvious counterexamples. Moreover, it is not the case that only humans possess reason, as the Stoics themselves seem to recognize when they characterize Zeus and the divine as rational (cf. Cicero, DF 3.67 above). Another challenge to humans as the exclusive possessors of reason can be found in the claim that there are "non-human persons" (Singer 2011: 94-100) - 
advanced mammals such as dolphins, whales, or apes, who use language and grasp inferences, employing something functionally equivalent to a rational mind. In short, if we take seriously the Stoic conception of reason, it is hard to see why all and only humans possess it (cf. Stephens 1994; Castelo 1996; Gill 2016).

In response to these objections, the Stoics could insist that "rational", in the claim that all and only humans are rational, should be understood as "the kind of being that naturally acquires and uses reason" (cf. Seneca Ep. 124.8-9). Children, adult accident victims, and the developmentally challenged would then count as rational - they are the kind of beings that naturally acquire reason, although they lack it at present - and Zeus and the divine would not, as these latter entities are never without reason and always use it perfectly (Cicero DND 2.21, 36, 39; Philo, SVF 3.372). When it comes to the non-human candidates for rationality, however, the Stoics seem to go along with the assumptions of their philosophical tradition (cf. Aristotle NE 10.8, 1178b25-28) and reject out of hand that any non-human could display the cognitive sophistication that is the hallmark of reason.

One may be tempted, then, to revise the Stoic view so that certain advanced mammals rise to the level of rationality. This would be to expand the boundaries of the cosmopolis beyond the human, but to retain rationality as the criterion of membership (cf. Epictetus Diss. 2.8.8). On this neo-Stoic view, advanced mammals, as reason-possessing creatures, would have a claim on items of value, and any fair distribution of indifferents would have to take their interests into account. Moreover, it would be open to these non-human reasoners to attain virtue and happiness, since the virtuous condition of rationality would no longer be found only among adult humans.

Alternatively, one might question the Stoic premise that rationality is the basis for intrinsic value. However, this is to reject the core of the Stoic theory, as one would have to abandon the orthodox Stoic justification for the existence of the cosmopolis - that there is a 
single city made up of all reasoners, since to have reason entails sharing the same set of basic social norms. Consequently, this view would have to start from the beginning and articulate a new rationale for moral consideration. The result, I suspect, would be a theory justifying additional cases of environmental protection but no longer recognizably Stoic. ${ }^{6}$

\section{Secondary Works Cited}

Brennan, T. (2005) The Stoic Life. Oxford: Oxford University Press.

Brennan, A. and Lo, Y-S. (2016) "Environmental Ethics”. In The Stanford Encyclopedia of Philosophy, Ed. E. Zalta. URL= <https://plato.stanford.edu/archives/win2016/entries/ethics-environmental/>.

Brunschwig, J. (1986) “The Cradle Argument in Epicureanism and Stoicism”. In Norms of Nature, Eds. M. Schofield, G. Striker, Cambridge: Cambridge University Press, $113-$ 144.

Campbell, I. (2018) “Animal Welfare and Environmental Ethics: It’s Complicated”. Ethics and the Environment 23(1): 49-69.

Castelo, C.V. (1996) "Reflections on Stoic Logocentrism”. Environmental Ethics 18(3): 291296.

Cheney, J. (1989) “The neo-stoicism of radical environmentalism”. Environmental Ethics 11(4): 293-325.

Cooper, J. (2012) “Stoicism as a Way of Life.” In his Pursuits of Wisdom. Princeton: Princeton University Press, 144-225.

---- (2004) “Stoic Autonomy." In his Knowledge, Nature, and the Good. Princeton: Princeton University Press, 204-245.

Frede, M. (1994) “The Stoic Conception of Reason.” In Hellenistic Philosophy, Ed K. Boudouris, Athens: International Center for Greek Philosophy and Culture, 50-63. 
Gill, C. (2016) "Stoicism and the Environment." Blog post. URL = <https://modernstoicism.com/stoicism-and-the-environment-by-chris-gill/> .

Goodpaster, K. (1978) “On Being Morally Considerable.” The Journal of Philosophy 75(6): 308-325.

Inwood, B. (1999) "Rules and Reasoning in Stoic Ethics." Topics in Stoic Philosophy. Ed. K. Ierodiakonou. Oxford: Oxford University Press, 95-127.

Jamieson, D. (2008) Ethics and the Environment: an Introduction. Cambridge: Cambridge University Press.

Klein, J. (2016) “The Stoic Argument from Oikeiosis.” Oxford Studies in Ancient Philosophy 50: $143-200$.

----- (2015) "Making Sense of Stoic Indifferents." Oxford Studies in Ancient Philosophy 49: 227-281.

Leopold, A. (1949) A Sand County Almanac. Oxford: Oxford University Press.

Long A.A. and Sedley, D. (1987) The Hellenistic Philosophers. Cambridge: Cambridge University Press. [= LS]

Magrin, S. (2018) "Nature and Utopia in Epictetus' Theory of Oikeiosis". Phronesis 63: 293350.

Naess, A. (1973) “The Shallow and the Deep, Long-Range Ecology Movement.” Inquiry 16: 95-100.

Norton, B. (1984) “Environmental ethics and weak anthropocentrism”. Environmental Ethics 6(2): 131-148.

Regan, T. (1981) “The Nature and Possibility of an Environmental Ethic”. Environmental Ethics 3 (1): 19-34.

Rolston. H. (1975) “Is there an ecological ethic?”. Ethics 85(2): 93-109. 
Routley, R. (1973) “Is There a Need for a New, an Environmental Ethic?”. Proceedings of the XVth World Congress of Philosophy 1: 205-210.

Sandler, R. (2007) Character and Environment: A Virtue-Oriented Approach to Environmental Ethics. New York: Columbia University Press.

Schofield, M. (1991) The Stoic Idea of a City. Cambridge: Cambridge University Press.

Sedley, D. (2007) Creationism and its Critics in Antiquity. Berkeley: University of California Press.

Singer, P. (2011) Practical Ethics. $3^{\text {rd }}$ ed. Cambridge: Cambridge University Press.

---- (1975) Animal Liberation: A New Ethics for Our Treatment of Animals. New York: Random House.

Stephens, W.O. (2014) “Epictetus on Beastly Vices and Animal Virtues”. In Epictetus: His Continuing Influence and Contemporary Relevance, D. Gordon and D. Suits (eds.). Rochester: RIT Press, 207-240.

----- (1994) “Stoic Naturalism, Rationalism, and Ecology”. Environmental Ethics 16(3): 275286.

Striker, G. (1987) “Origins of the Concept of Natural Law”. Boston Area Colloquium in Ancient Philosophy 2: 79-94.

Taylor, P. (1986) Respect for Nature: A Theory of Environmental Ethics. Princeton: Princeton University Press.

Vogt, K.M. (2008) Law, Reason, and the Cosmic City: Political Philosophy in the Early Stoa. Oxford: Oxford University Press. 
${ }^{1}$ The Stoics view the possession of reason as the sole "morally relevant criterion": $\mathrm{cf}$. Goodpaster 1978. Thus Epictetus says of the donkey that, if it were to acquire reason, "it would no longer be subject to us... but would be our equal and peer" (Diss. 2.8.8). Note that, strictly speaking, the Stoics hold that the gods, as well as humans, possess rationality. So it is only among non-divine entities that humans are alone in possessing reason. I set aside this complication for now but will return later on to consider some implications of divine rationality.

${ }^{2}$ Cicero here mentions gods, as well as humans, as the beings for whose sake animals are created (see also DND 2.133, 154). And elsewhere the gods are included among the citizens of the cosmopolis (DND 2.78-79, 154). These claims are important for understanding why humans must contemplate and study the cosmos, as a perfect creation of the gods and instantiation of rational order and beauty, but not for understanding what we owe to nonhuman animals and plants. As DL 7.129 confirms, "anthropocentric" is thus an apt label for the Stoic theory of environmental value, in the sense relevant to contemporary environmental ethics.

${ }^{3}$ See Sandler 2007 for a contemporary articulation of virtue-based environmental ethics.

${ }^{4}$ Note that here again I am restricting consideration to non-divine entities.

${ }^{5}$ This important passage is also discussed by Magrin 2018: 299-300 and Stephens 2014: 213 215. See also Cicero DND 2.153. On my interpretation, the Stoics defend a kind of "weak anthropocentrism", insofar as they view nature not only as a "mere satisfier of fixed and often consumptive values [but] also [as] an important source of inspiration in value formation" (Norton 1984: 135). 
${ }^{6}$ For helpful discussion and generous feedback on earlier drafts, I would like to thank Richard Hutchins, Alex Bolton, Christopher Gill, and Ian Campbell. I am also grateful to the audience of the Oriel College Classics Society for their incisive questions. 